\title{
A COMPACT ULTRA-WIDE BAND PATCH ANTENNA USING DEFECTED GROUND STRUCTURE
}

Mekala Harinath Reddy MSc Student, Department of Engineering, University of Leicester. Leicester, (United Kingdom).

E-mail: harinath.m1995@gmail.com. ORCID: https://orcid.org/0000-0003-0321-5421

D. Sheela

Professor, Department of ECE, Saveetha School of Engineering, Saveetha University, Chennai, (India).

E-mail: dsheelatagorerandd@gmail.com. ORCID: https://orcid.org/0000-0002-0974-3922

\section{Citación sugerida:}

Reddy, M. H., y Sheela, D. (2021). A compact ultra-wide band patch antenna using defected ground structure. 3C Tecnología. Glosas de innovación aplicadas a la pyme, Edición Especial, (noviembre, 2021), 567577. https://doi.org/10.17993/3ctecno.2021.specialissue8.567-577 


\section{ABSTRACT}

Microstrip patch antennas are by and large broadly utilized in the majority of the wireless communication systems because of its lightweight, minimal effort and simplicity of establishment, so they assume an overwhelming job in the advanced communication systems. In this paper, we propose a reduced patch antenna for ultra-wide band applications. The proposed patch antenna design resonates between $2.26 \mathrm{GHz}$ to $9.55 \mathrm{GHz}$. To accomplish ultra-wide band a defected ground is used in the proposed design. Throughout the resonating wide band, the minimum reflected power obtained is $-49 \mathrm{~dB}$ at $5.8 \mathrm{GHz}$ which is a ISM band and the VSWR is below 2. The obtained gain is greater than $3 \mathrm{~dB}$ thought out the band and the highest gain is obtained at 9.5 GHz i.e., $5.7 \mathrm{~dB}$. Also, the proposed design has good radiation characteristics both at azimuthal plane and elevation plane. HFSS software is used for simulating the design.

\section{KEYWORDS}

Bandwidth, Defected Ground, Reflected Power, Ultra-Wide Band, VSWR. 


\section{INTRODUCTION}

In ongoing remote communication systems high information rate have turned into a basic prerequisite. Channel assignment for enormous measure of information transmission utilizing low recurrence groups has almost incomprehensible. To conquer this disadvantage research is being directed to utilize high frequency bands namely UWB. Now a days due to low cost, small size and high data rate features ultra-wide band (UWB) antennas have pulled in much consideration among researchers. For unlicensed ultra-wide band applications, the federal commission has allotted $3.1 \mathrm{GHz}$ to $10.6 \mathrm{GHz}$. There are many ways of obtaining ultra-wideband; use of slotting technique is one among the mostly used design technique for the UWB achievement. But apart from slotting technique use of Defected Ground Structure (DGS) technique is one of the recent and efficient ways of obtaining UWB.

In this article, we portray a microstrip patch antenna design for UWB applications by utilizing a method called Defected Ground Structure (DGS). Simplified form of electromagnetic band gap structure can be regarded as DGS. The name DGS means simply "defect" that has been placed on the ground. Slot in the ground metal is basic element of DGS. DGS was first proposed by Kim and Park. In depicting a solitary unit of dumbbell-shaped deformity he utilized the term 'DGS. In 2005 to improve radiation characteristics, the DGS was directly integrated with microstrip resonator. Due to its easy implementation and compact nature DGS is being used in different applications. Among antenna engineers, this popular technique has grown immensely.

\section{DESIGN METHODOLOGY}

The antenna is intended for ultra-wide band applications. The proposed antenna configuration is shown in the Figure 1 and top and base view is shown in Figure 2. Here, rectangular patch is the emanating element, which is printed on a substrate with relative permittivity 2.2. The thickness used for the substrate is $1.6 \mathrm{~mm}$. Excitation is done using lumped port of $50 \mathrm{ohms} \mathrm{impedance} \mathrm{and} \mathrm{the} \mathrm{type} \mathrm{of} \mathrm{feed} \mathrm{that} \mathrm{is} \mathrm{used} \mathrm{is} \mathrm{inset} \mathrm{feed.} \mathrm{The}$ dimensions that are used are listed in Table 1. 


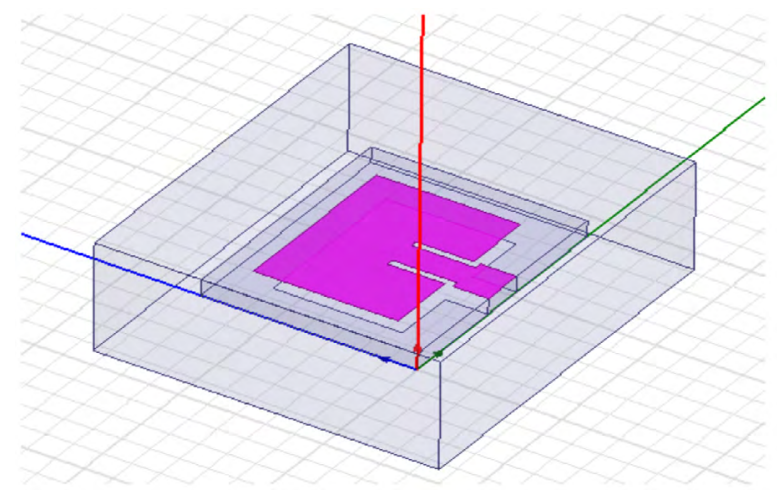

Figure 1. Proposed antenna design.

Source: own elaboration.

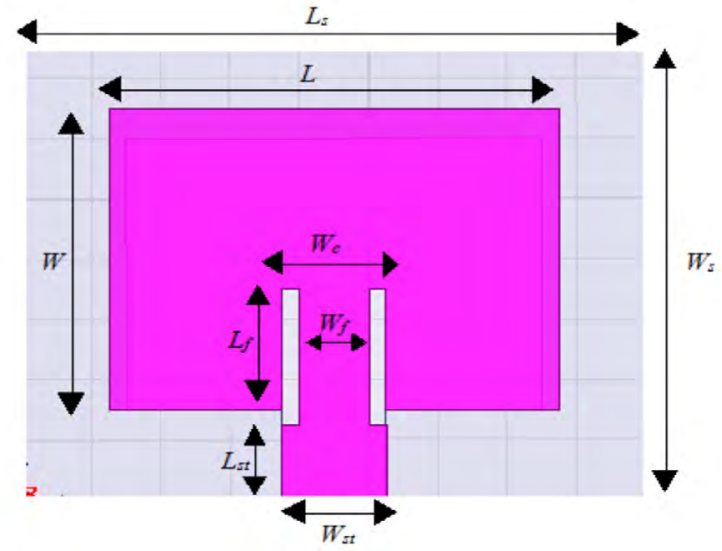

(a)

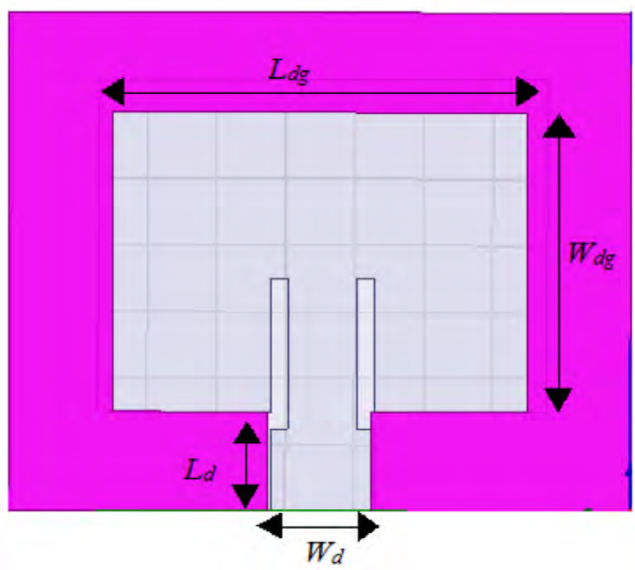

(b)

Figure 2. (a) Top side view, (b) base side view of proposed design.

Source: own elaboration. 
In the proposed design defected ground is nothing but the slot. A rectangular slot defect is introduced on the ground with the dimensions ( $\operatorname{Ldg} \mathrm{x} \mathrm{Wdg})$ as mentioned in the Table 1. Along with this slot another rectangular slot with the dimensions ( $\mathrm{Ld}$ x Wd) is loaded exactly straight to the transmission line on the ground. These two slots are united together which together acts as defected ground structure. To calculate the proposed design dimensions, design equations have been taken from Matin (2008).

Table 1. Dimensions of proposed antenna design.

\begin{tabular}{|c|c|c|c|}
\hline PARAMETERS & VALUES $(\mathbf{m m})$ & PARAMETERS & VALUES $(\mathbf{m m})$ \\
\hline Ls & 18 & $\mathbf{W c}$ & 3 \\
\hline $\mathbf{W s}$ & 15 & Lst & 3 \\
\hline $\mathbf{h}$ & 1.6 & $\mathbf{W s t}$ & 2.5 \\
\hline $\mathbf{L}$ & 13 & Ldg & 12 \\
\hline $\mathbf{W}$ & 10 & $\mathbf{W d g}$ & 9 \\
\hline Lf & 4 & Ld & 3 \\
\hline Wf & 2 & Wd & 3 \\
\hline
\end{tabular}

Source: own elaboration.

\section{SIMULATION RESULTS}

The design is implemented and simulated using HFFS 13. The parameters like reflection coefficient, VSWR, Bandwidth, radiation pattern and Gain are considered for the proposed antenna. The return loss S1 1 of the proposed antenna is shown in Figure 3. The resonance band 2.26 GHZ-9.55 GHz is obtained in the simulation with a minimum return loss of -49 $\mathrm{dB}$ at $5.8 \mathrm{GHz}$. It is noted that with the use of defect on the ground ultra-wide band has been obtained and the obtained bandwidth is $7.29 \mathrm{GHz}$.

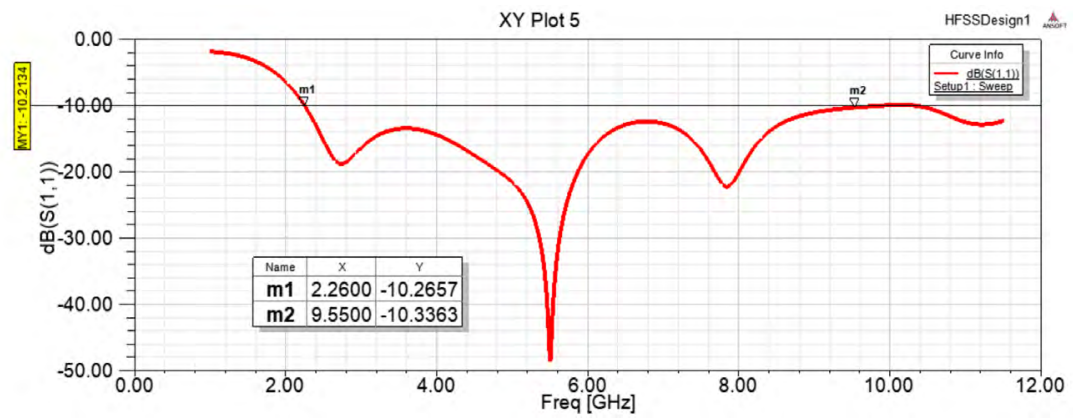

Figure 3. Return loss S11 of proposed design.

Source: own elaboration. 
For any antenna VSWR is the most significant consideration. Practically the VSWR for every antenna should be less than 2 and when its value is equal to 1 then there would be a 100 percent perfect impedance matching between patch and the feed line. The VSWR plot is shown in the figure 4 and its value is found to be below 2 throughout the resonance band.

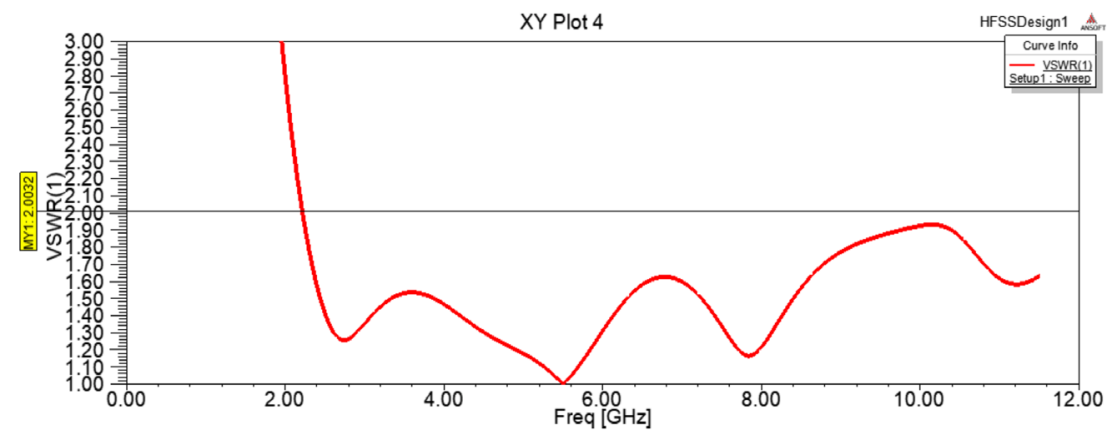

Figure 4. VSWR Plot.

Source: own elaboration.

Gain is the most important considerations in antenna because they describe the direction capabilities. It represents the antenna's radiation characteristics. For the proposed design, gain plots at various frequencies are shown in Figure 5.

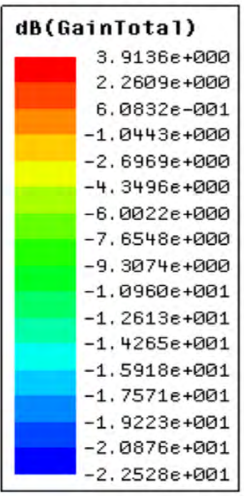

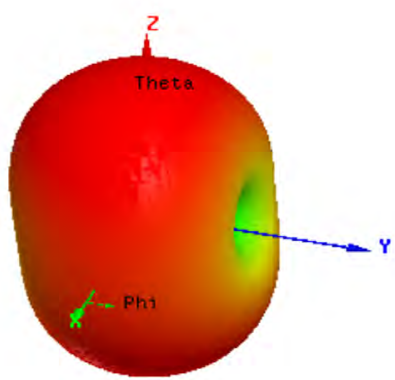

(a) 


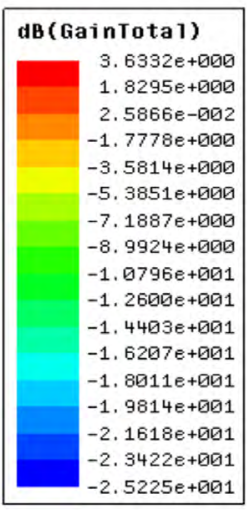

dB (GainTota1)

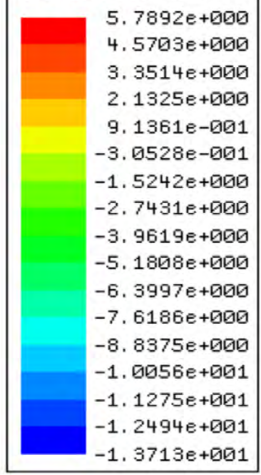

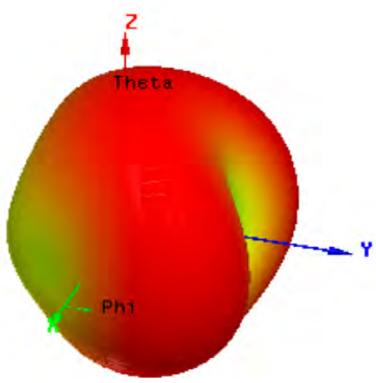

(b)

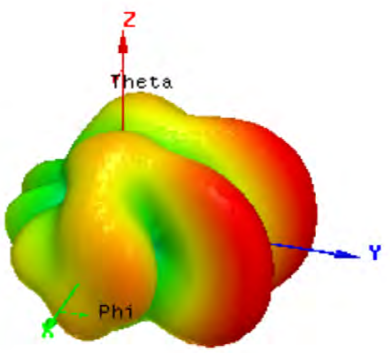

(c)

Figure 5. Gain at (a) $2.4 \mathrm{GHz}$, (b) $5.8 \mathrm{GHz}$ and (c) $9.5 \mathrm{GHz}$.

Source: own elaboration.

From the gain simulation results, it tends to be seen that the gain at the frequencies 9.5 $\mathrm{GHz}, 5.8 \mathrm{GHz}$ and $2.4 \mathrm{GHz}$ is gotten to be $3.9 \mathrm{~dB}, 3.6 \mathrm{~dB}$ and $5.78 \mathrm{~dB}$.

The radiation pattern of the wide band antenna is appeared in Fig 6 at various frequencies9.5 $\mathrm{GHz}, 5.8 \mathrm{GHz}$ and $2.4 \mathrm{GHz}$. From the figure it is seen that antenna has unidirectional radiation pattern at E-plane (phi $=0 \mathrm{deg}$ ) and bidirectional radiation pattern at $\mathrm{H}$ - Plane (phi $=90 \mathrm{deg})$ at all the frequencies. 


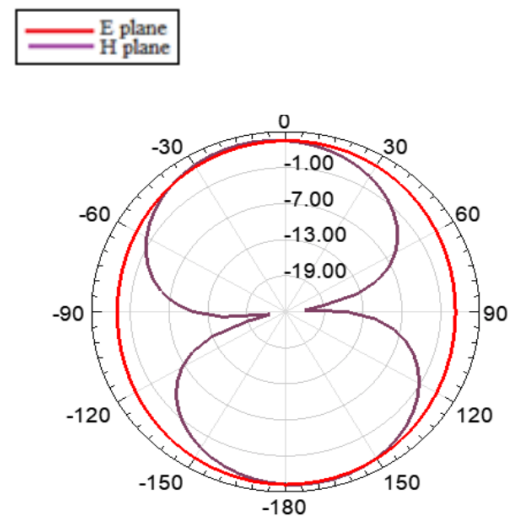

(a)

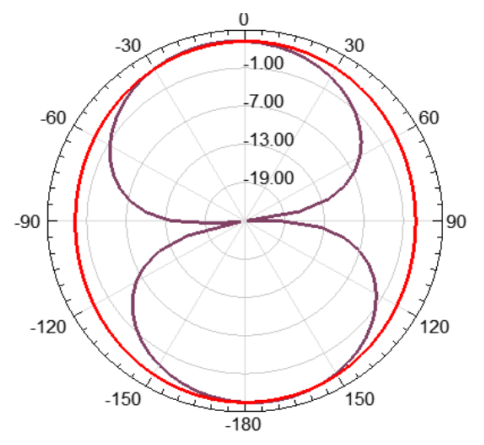

(b)

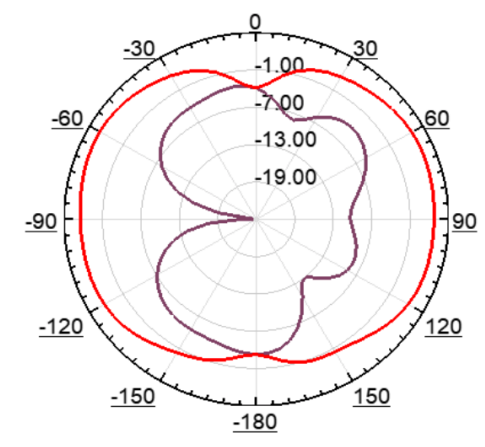

(c)

Figure 6. Radiation Pattern (a) $2.4 \mathrm{GHz}$, (b) $5.8 \mathrm{GHz}$ and (c) $9.5 \mathrm{GHz}$.

Source: own elaboration.

\section{CONCLUSIONS}

A minimized design using absconded ground structure is proposed for ultra-wide band applications and the deformity that is used on the ground is rectangular slot. The proposed antenna shows great UWB qualities with its outcomes resonating between $2.26 \mathrm{GHz}$ and 9.55 GHz and VSWR less than 2. The antenna has omnidirectional radiation pattern at E-Plane and bidirectional radiation pattern at H-Plane. This study has been made on designing a compact UWB antenna with enhanced performance. This antenna can be utilized in commercial wide band applications and UWB systems. Moreover, the antenna is of a very compact in size, which can be easily installed in portable devices. 


\section{REFERENCES}

Dinh, N. Q. (2014). A proposal of a compact ultra-wide band antenna works as a magnetic dipole. In 2014 International Conference on Advanced Technologies for Communications (ATC 2014) (pp. 577-581). IEEE. https:/ / www.semanticscholar.org/paper/A-proposal-ofa-compact-Ultra-Wide-Band-antenna-as-Trung-Dinh/64a512cb6d484ac16d77670 $582596 \mathrm{~b} 221 \mathrm{c} 474 \mathrm{dfb}$

Fallahi, R., Kalteh, A. A., \& Roozbahani, M. G. (2008). A novel UWB elliptical slot antenna with band-notched characteristics. Progress In Electromagnetics Research, 82, 127-136. https:/ /www.jpier.org/PIER/pier.php?paper=08022603

Matin, M. A. (2008). Stacked E-shaped patch antenna for lower-band ultrawideband (UWB) applications. In 2008 IET International Conference on Wireless, Mobile and Multimedia Networks. https://ieeexplore.ieee.org/document/4470062

Reddy, M. H., Joany, R. M., Manikandan, G., \& Nisha, A. S. A. (2017). Design of microstrip patch antenna with multiple slots for satellite communication. In 2017 International Conference on Communication and Signal Processing (ICCSP) (pp. 08300834). IEEE. https://www.semanticscholar.org/paper/Design-of-microstrip-patchantenna-with-multiple-Reddy-Joany/82802c410dcb2342988e40c95930878615a39 dfd

Reddy, M. H., Sheeba, R., \& Niba, S. T. (2017). Design Of Microstrip Patch Antenna For Space Environment With Minimum Returnloss. Research fournal Of Pharmaceutical Biological And Chemical Sciences, 8(2), 2673-2678. https://www.rjpbcs.com/ pdf/2017_8(2)/[300].pdf

Siriwongpairat, W. P., \& Liu, K. R. (2007). Ultra-wideband communications systems: multiband OFDM approach. John Wiley \& Sons.

Sugadev, M., \& Logashanmugam, E. (2015). Quad Band U-Slot Microstrip Antenna for $\mathrm{C}, \mathrm{X}$ and $\mathrm{Ku}$ Band Wireless Applications. Contemporary Engineering Sciences, 8(16), 737-745. http://www.m-hikari.com/ces/ces2015/ces13-16-2015/p/ sugadevCES13-16-2015.pdf 
Zehforoosh, Y., Ghobadi, G., \& Nourinia, J. (2006). Antenna design for ultra wideband application using a new multilayer structure. PIERS online, 2(6), 544-549. https:// www.researchgate.net/publication/245554186_Antenna_Design_for_Ultra_ Wideband_Application_Using_a_New_Multilayer_Structure 
